\title{
DIREITO E EDUCAÇÃO: A "CO-LABORAÇÃO" PARA A TRANSFORMAÇÃO DAS DIMENSÕES HUMANAS E SOCIAIS NA BUSCA DA EFETIVIDADE DO EXERCÍCIO DA CIDADANIA
}

\author{
LAW AND EDUCATION: THE "COLLABORATION" FOR THE \\ TRANSFORMATION OF THE HUMANITIES AND SOCIAL DIMENSIONS IN \\ SEARCH OF CITIZENSHIP OF THE EXERCISE OF EFFECTIVENESS
}

\author{
${ }^{1}$ Renata Aparecida Follone \\ ${ }^{2}$ Rubia Spirandelli Rodrigues
}

\section{RESUMO}

O presente trabalho foi inspirado na Lei de Diretrizes Básicas e em Projetos de Extensão desenvolvidos junto ao Departamento de Pesquisa e Extensão da Universidade do Estado de Minas Gerais-Unidade de Frutal-MG, os quais recepcionaram as pesquisas inseridas na temática Educação, Direito, Constituição, Justiça e Cidadania. O trabalho analisou e abordou a educação como instrumento de "co-laboração" e o reconhecimento de cada ser humano dentro da sociedade em que vive como sujeito de direitos e deveres com o propósito de se ampliar o estudo e saber na sociedade contemporânea, pelo acadêmico de direito junto aos alunos do ensino médio público.

Palavras-chave: Educação, Direito, "co-laboração", Transformação das dimensões humanas e sociais, Lei de diretrizes básicas da educação

\begin{abstract}
This work was inspired by the Basic Guidelines Law and developed Extension Project, with the Department of Research and Extension of the University of Minas-Unit Mining FrutalMG, which welcomed the inserted research in Education, Law theme, Constitution, Justice and Citizenship. The study analyzed and addressed education as a co-working of the instrument and the recognition of every human being in the society in which he lives as a subject of rights and duties in order to expand the study and knowledge in contemporary society, the academic law to the students of public high school.
\end{abstract}

Keywords: Education, Law, "co-laboring", Transformation of the human and social dimensions, Education law of basic guidelines

\footnotetext{
${ }^{1}$ Mestre em Direitos Coletivos e Cidadania pela Universidade de Ribeirão Preto - UNAERP, Ribeirão Preto - SP (Brasil). Professora da Universidade do Estado de Minas Gerais - UEMG, Belo Horizonte - MG (Brasil).

E-mail: rfollone@uol.com.br

${ }^{2}$ Mestre em Direitos Coletivos e Cidadania pela Universidade de Ribeirão Preto- UNAERP, Ribeirão Preto - SP (Brasil). Professora da Universidade do Estado de Minas Gerais- UEMG, Belo Horizonte - MG (Brasil).

E-mail: rubiaspirandelliadv@ hotmail.com
} 


\section{INTRODUÇÃO}

As pesquisas que deram origem a este artigo tiveram por escopo analisar e abordar a educação como instrumento de "co-laboração" para a transformação das dimensões humanas e sociais na busca da efetividade do exercício da cidadania, bem como proporcionar o reconhecimento de cada ser humano dentro da sociedade em que vive como sujeito de direitos e deveres.

O propósito foi valer-se do conhecimento jurídico, ministrados pelos professores do curso de direito da Universidade do Estado de Minas Gerais-Unidade Frutal aos acadêmicos do respectivo curso e com a participação efetiva destes, sob a orientação de docentes, em levarem aos alunos do ensino médio da Escola Estadual Maestro Josino de Oliveira de $1^{\mathrm{o}}$. E $2^{\mathrm{o}}$. Graus, estabelecida na cidade de Frutal, noções básicas de direito e a conscientização do indivíduo como cidadão na sociedade contemporânea. Assim, possibilitando à sociedade acesso aos conhecimentos fundamentais e básicos jurídicos, dentro das limitações do leigo, sobre o conceito de cidadania: o que é ser cidadão, bem como os direitos resguardados a ele e o amparo que a Constituição Federal e as leis em geral oferecem e o seu lugar como sujeito de direitos; a noção de Justiça, em uma dimensão mais moderna, na busca do bem-estar individual com reflexo na sua vida como um todo e com o objetivo principal de se fazer reconhecer o direito básico de cada um, bem como viabilizar um instrumento educacional capaz de minimizar, ao menos inicialmente, as desigualdades tão latentes na realidade em que vivemos.

O intuito básico foi desenvolver uma relação de colaboração entre os universitários do curso de Direito da UEMG/Unidade Frutal-MG e a comunidade, por meio de alunos da rede pública estadual de ensino, visando, também, auxiliar os educadores da rede pública de ensino na formação de cidadãos conhecedores dos seus direitos e sabedores dos seus deveres e, com isso, buscar uma horizontalidade em um encadeamento de ideias assimétricas, ou seja, EDUCAÇÃO-CIDADANIA-JUSTIÇA. Possibilitando a convergência dessas ideias em um contexto simétrico para o saber.

Partindo desses conceitos jurídicos, para a construção do novo em "co-laboração"1 de conhecimentos e saberes da Educação com o Direito e vice-versa, ensinando e reproduzindo um encontro de resultados, de aprendizados, ou seja, uma co-laboração entre os dois institutos em trabalharem juntos para facilitar a comunicação de informação e 
aprendizagem, com o objetivo de se atingir a transformação das dimensões humanas e sociais.

Relevante é que atualmente, as grades curriculares das escolas, públicas e privadas, não apresentam, em seus conteúdos, qualquer matéria ou disciplina que trate sobre direitos básicos da pessoa ou do cidadão. Porém, a Lei de Diretrizes e Bases da Educação - Lei nº.

9.394/96, conhecida pela sigla "LDB” - autoriza a inclusão de disciplinas na parte diversificada em atendimento aos interesses locais da comunidade, inclusive oferece grande autonomia aos sistemas de ensino para formar o seu currículo.

Assim, sendo o Direito um tema de grande interesse público, demonstramos, neste trabalho, que a "co-laboração" Educação e Direito viabiliza a inclusão de noções básicas de Direito no currículo escolar da educação básica, seja no ensino fundamental, médio ou de jovens e adultos, seja em escolas públicas, privadas, filantrópicas, comunitárias ou confessionais.

Partindo da Lei e dos projetos de extensão desenvolvidos é possível agregar a disciplina "Noções Básicas de Direito", ou outra denominação semelhante, na parte diversificada da grade curricular escolar, conforme autoriza ou permite a Lei de Diretrizes e Bases da Educação (LDB) - Lei nº. 9.394/96.

Reconhecemos que o tema é inovador, no sentido de que raramente alguma grade curricular existente já possua uma disciplina que trate de noções básicas de Direito, embora a Lei de Diretrizes Básicas da Educação preveja e possibilite referida inclusão.

O presente artigo, tanto pela atualidade como pela relevância do tema, procura atender a necessária e importante discussão e reflexão da interface do Direito com a Educação e da Educação com o Direito, imprescindível à efetividade da liberdade e da igualdade como garantias fundamentais. A liberdade como direito fundamental de viver livremente e de fazer escolhas. E, a igualdade reconhecida como o direito de ter acesso a oportunidades equânimes em relação aos demais membros da sociedade.

1 Portanto, o sentido de colaborar, que vem do latim “colaborare” é o mesmo que ajudar, trabalhar junto, ou seja, "laborare", que é trabalhar, fatigar-se. 
Como conclusão, apresentamos as considerações e viabilidade oriundas das pesquisas realizadas, com a singela e modesta intenção de contribuir para que a "colaboração" da Educação e do Direito e vice-versa, traga a efetivação da transformações das dimensões humanas e sociais.

\section{DIREITO À EDUCAÇÃO: FUNDAMENTO PARA SE FORMAR CIDADÃOS}

Um grande passo foi dado no setor da educação com a Constituição Federal de 1988, a perspectiva política e a natureza pública da educação são realçadas, não apenas pela expressa definição de seus objetivos, mas também, pela própria estrutura de todo o sistema educacional.

A Constituição da República Federativa do Brasil de 1988 tentou dar conta das profundas mudanças ocorridas, assim,

\footnotetext{
Nosso país na economia, nas relações de poder e nas relações sociais globais, nos últimos 20 anos, introduzindo temas, redefinindo papéis, incorporando às instituições sociais segmentos historicamente marginalizados, sem, no entanto, alterar substantivamente as relações sociais vigentes (NEVES, L. M. W., 1999, p.99).
}

O direito à educação, na Constituição Federal de 1988, como um direito social no artigo $6^{\circ}$; especifica a sua competência legislativa nos artigos 22 , XXIV e 24, IX; dedica toda uma parte do título da Ordem Social para responsabilizar o Estado e a família, ainda, faz menção significativa quanto ao acesso e a qualidade, organizando o sistema educacional, distribuindo encargos e competências para os entes da federação.

A educação é, assim, "um direito social fundante da cidadania e o primeiro na ordem das citações" (CURY, C. R. J., 2002, n. 116, p. 245-262). Isso equivale dizer que sem educação não pode haver cidadania. Também, o pleno exercício da democracia encontrar-se-á entravado se este direito social não for amplamente assegurado à população.

No que concerne à educação, assegurada constitucionalmente, o titular desse direito é uma pessoa de qualquer idade, que teve ou não acesso à escolaridade obrigatória na idade própria. O sujeito deste direito é o indivíduo e o sujeito do dever é o Estado.

A nossa Constituição Federal vigente buscou dar o devido valor ao tema, pois só com a educação é possível formar cidadãos capazes de gerir a sociedade, de exigir seus direitos e cumprir seus deveres, formando uma sociedade mais justa e igualitária. 
Assim, o texto constitucional trouxe além da garantia, também, instrumentos que podem garantir a efetividade da aplicação desse direito,

\begin{abstract}
Além do regramento minucioso, a grande inovação do modelo constitucional de 1988 em relação ao direito à educação decorre de seu caráter democrático, especialmente pela preocupação em prever instrumentos voltados para sua efetividade (RANIERI, 2000, p. 78).
\end{abstract}

$\mathrm{O}$ direito à educação está dentro do contexto dos direitos sociais, econômicos e culturais, os chamados direitos de Segunda Dimensão, no âmbito dos direitos fundamentais.

A expressão direitos fundamentais guarda sinonímia com a expressão direitos humanos. São direitos que encontram seu fundamento de legitimidade na condição digna do ser humano. São direitos reconhecidos pelo ordenamento jurídico como indispensáveis para a própria manutenção da condição humana.

O direito à educação representa instrumento hábil de produção e enriquecimento de conhecimento, um processo onde se busca descobrir a realidade a partir da convivência humana, daí sua qualidade de fundamental, de essencial para a vida em sociedade.

O processo educacional proporciona o reconhecimento do papel do homem na história, fazendo com que este perceba que ele faz a história. Nesse sentido, forma-se um elo entre direitos fundamentais e cidadania por meio da educação.

No que concerne à "fundamentalidade", (1992, p. 05) Bobbio destaca que os direitos fundamentais ou direitos humanos são direitos históricos, ou seja, são frutos de circunstâncias e conjunturas vividas pela humanidade e, especificamente, por cada um dos diversos Estados, sociedades e culturas. Portanto, embora se alicercem numa perspectiva jusnaturalista, os direitos fundamentais não prescindem do reconhecimento estatal, da inserção no direito positivo.

A compreensão do direito à educação na ordem constitucional de 1988 é inerente ao reconhecimento da dignidade da pessoa humana como fundamento da República Federativa do Brasil, bem como com os seus objetivos, especialmente no que se refere: a construção de uma sociedade livre, justa e solidária, o desenvolvimento nacional, a erradicação da pobreza e da marginalidade, redução das desigualdades sociais e regionais e a promoção do bem comum.

A forma constitucional dada ao direito à educação está diretamente ligada à busca da tão sonhada igualdade que caracteriza os direitos de segunda dimensão, como já mencionado. Os direitos sociais compreendem um sentido de igualdade que se realiza por meio da atuação estatal dirigida à garantia de padrões mínimos de acesso a bens econômicos, sociais e culturais. 
Nesse contexto, oportuno delinear em linhas gerais a distinção entre a perspectiva subjetiva e objetiva dos direitos fundamentais.

A ideia vinculada à perspectiva subjetiva dos direitos fundamentais consiste na “possibilidade que tem o titular (...) de fazer valer judicialmente os poderes, as liberdades ou mesmo o direito de ação ou às ações negativas ou positivas que lhe foram outorgadas pela norma consagradora do direito fundamental" (SARLET, 1998.p. 152) em questão. Tal perspectiva tem como referência a função essencial dos direitos fundamentais, que consiste na proteção do indivíduo.

No panorama da perspectiva objetiva entende-se como o reconhecimento dos direitos fundamentais como "decisões valorativas de natureza jurídico-objetiva da Constituição, com eficácia em todo o ordenamento jurídico e que fornecem diretrizes para os órgãos legislativos, judiciários e executivos" (SARLET, 1998, p. 140). Superando-se a dimensão de proteção do indivíduo, compondo uma nova função para os direitos fundamentais que abrange a tutela da própria comunidade.

Diante de uma sociedade globalizada, a descrição de direito fundamental do direito à educação se destaca. Sob a perspectiva individual, acentua-se na exigibilidade direta pelo cidadão e no plano objetivo concretiza no dever do Estado em promovê-la com efetividade. Se no plano subjetivo se resguarda o desenvolvimento da personalidade humana e mesmo a qualificação profissional, no plano objetivo o direito à educação se afirma indispensável ao próprio desenvolvimento da sociedade como um todo.

Assim, na Constituição Federal observamos que a cidadania não está ligada, tão somente, ao exercício ao voto, mas sim, que cidadania refere-se ao cidadão dentro de um todo, como dispõe o artigo 205, da Constituição Federal de 1988, a qual é conhecida como a Constituição Cidadã

A educação, direito de todos e dever do Estado e da família, será promovida e incentivada com a colaboração da sociedade, visando ao pleno desenvolvimento da pessoa, seu preparo para o exercício da cidadania e sua qualificação para o trabalho. (BRASIL, 1988)

Ao tratarmos de educação e seus fundamentos para a cidadania, é notório que a educação é essencial à formação da cidadania democrática, sendo esta entendida como a concretização dos direitos políticos, civis e sociais que permitem ao indivíduo a inserção na sociedade. 
A Cidadania tem um conceito amplo que aborda desde a participação do cidadão na comunidade de forma integral até a incorporação dos direitos civis, sociais e econômicos de cada indivíduo, resguardando seus direitos, e estabelecendo seus deveres, que é de suma importância para a aplicabilidade completa da cidadania na sociedade. Assim, é de grande relevância abordar que a constituição não evoluiu apenas com a evolução linear do constitucionalismo democrático, mas também, da soberania, cidadania, dignidade da pessoa humana, valores sociais do trabalho e da livre iniciativa, pluralismo político.

Em outra dimensão, Justiça como condição contemporânea de vida que proporciona o bem-estar geral e particular de cada cidadão, que por estas condições asseguradas pela sociedade podem desenvolver todo o seu potencial individual, familiar, profissional e social, tendo assento esse último sentido no fundamento da igualdade, valor e dignidade pessoal do homem.

\section{O DIREITO COMO FATO SOCIAL E CULTURAL NO CONTEXTO DAS DIRETRIZES CURRICULARES NACIONAIS}

O tema Educação sempre foi cativante e envolvente porque se refere à prática intermitente e contínua de transmissão e recebimento de informações construídas com o tempo, as quais influenciam o homem e o ajudam a desenvolver e transformar o meio em que vive e, ainda, a desenvolver-se, figurando como instrumento extremamente hábil para o pleno desenvolvimento da pessoa (LIMA, 2003, p. 1-2).

\subsection{Diretrizes curriculares nacionais}

Como é dedico, a educação de qualidade é um pressuposto essencial previsto na Lei $\mathrm{n}^{\circ}$. 9.394, de 20 de dezembro de 1996, bem como está disposto nas Diretrizes Curriculares Nacionais do Ministério da Educação, dizendo que

\footnotetext{
A Educação Básica de qualidade é um direito assegurado pela Constituição Federal e pelo Estatuto da Criança e do Adolescente. Um dos fundamentos do projeto de Nação que estamos construindo, a formação escolar é o alicerce indispensável e condição primeira para o exercício pleno da cidadania e o acesso aos direitos sociais, econômicos, civis e políticos. A educação deve proporcionar o desenvolvimento humano na sua plenitude, em condições de liberdade e dignidade, respeitando e valorizando as diferenças. (BRASIL, Ministério da Educação)
} 
Percebemos, pela leitura do texto acima, que a formação promovida pela escola deve objetivar o exercício pleno da cidadania, assim como o acesso aos direitos sociais, econômicos, civis e políticos, primar pelo desenvolvimento da pessoa com liberdade e dignidade.

No mesmo sentido, podemos citar os Parâmetros Curriculares Nacionais que também se posicionaram a favor de construir referências comuns em todo o Brasil e, por esse modo, dar condições de acesso a conhecimentos para que o educando exerça a cidadania

\begin{abstract}
Os Parâmetros Curriculares Nacionais foram elaborados procurando, de um lado, respeitar diversidades regionais, culturais, políticas existentes no país e, de outro, considerar a necessidade de construir referências nacionais comuns ao processo educativo em todas as regiões brasileiras. Com isso, pretende-se criar condições, nas escolas, que permitam aos nossos jovens ter acesso ao conjunto de conhecimentos socialmente elaborados e reconhecidos como necessários ao exercício da cidadania. (BRASIL, Secretaria de Educação Fundamental-MEC )
\end{abstract}

Segundo os Parâmetros Curriculares Nacionais, a educação deve proporcionar a utilização de múltiplas linguagens e conhecimentos sociais pelos alunos, assim

É igualmente importante que ela favoreça a produção e a utilização das múltiplas linguagens, das expressões e dos conhecimentos históricos, sociais, científicos e tecnológicos, sem perder de vista a autonomia intelectual e moral do aluno, como finalidade básica da educação. (BRASIL, Secretaria de Educação Fundamental-MEC)

Entre essas linguagens e conhecimentos sociais está incluído o Direito, pois este é uma ciência social, construída e aplicada na realidade da sociedade e, portanto, dos alunos, em diversos contextos da sua vivência social.

\title{
3.2 O direito como ciência social aplicada na educação
}

O Direito como ciência social é destacado pela conceituação de Reis Friede (2009, p.248), que ensina

Neste diapasão, resta fundamental assinalar que, num espectro analítico mais adequado, a Ciência do Direito tem sido corretamente classificada como efetiva ciência social, de nítida feição hermenêutica, considerando, especialmente, não só possuir foco de observação em fenômenos sociais e culturais, mas, sobretudo, por desenvolver um sistema peculiar de interpretação de fatos sociais e culturais que não se limita, de nenhuma maneira, à simples valoração intrínseca dos mesmos, concebendo norma (fase legislativa), mas, ao contrário, permite ultrapassar a concepção fundamental interpretativa, reprocessando a conclusão (ou, em outras palavras, a própria norma) e concebendo, desta feita, uma segunda norma (de aplicação) no contexto de um sinérgico processo hermenêutico (fase judicial). 
Portanto, correto dizer que o Direito é ciência social já consolidada na realidade, pois podemos observar que a Ciência Jurídica parte do fato social ou cultural para, ao ser valorado, tornar-se norma e, por consequência, esta poderá ser novamente reprocessada e se transformar em uma segunda norma, mais atual e sujeita às modificações comuns nas demais ciências.

Reis Friede, também, afirma que as dúvidas antes existentes quanto à cientificidade do Direito foram completamente eliminadas, pois

\begin{abstract}
o que aparenta ter sido dúvida primaz no passado parece ter se transformado em inconteste certeza no presente, permitindo que o Direito - a par de toda a sorte de inegáveis especificidades - se posicione, com invejável segurança, na atualidade contemporânea, em um tipo particular de ciência, com características especiais (hermenêutica, comportamental (projeção de um mundo ideal (meta do dever-ser)) e axiológica), mas nem por isso distante do factum característico fundamental de todas as ciências, ou seja, a busca permanente e contínua pela verdade, através da interpretação de fatos (naturais ou sociais), por intermédio da necessária e insuperável valoração intrínseca de um dado fenômeno, originando uma norma ou tese (explicativa e/ou comportamental). (FRIEDE, 2009, p. 249)
\end{abstract}

É de grande relevância mencionarmos a brilhante lição de Maria Helena Diniz (2008, p. 359), quando a jurista distingue, com uma objetividade simples e certeira, a diferença entre a norma ética e a lei física ou natural, ou seja, a norma jurídica é regra de conduta e que regula comportamentos que as pessoas e grupos devem seguir e obedecer, comportando um comando imperativo a todos, na verdade, impõe um dever.

Dessa forma, segue explicando Maria Helena Diniz (2008, p. 361), que o Direito está situado no campo das normas éticas, composto por comandos pertinentes às condutas, às ações e aos comportamentos de pessoas no meio social, com base em valores predeterminados a serem preservados e respeitados pela sociedade.

Daí se depreende a diferença fundamental entre norma ética, a que prescreve um dever-ser, e a lei física ou natural, que é a lei do ser (do que é na natureza) é a força da imperatividade, ou seja, a lei natural somente é do jeito que existe por si só e não se submete a nenhuma vontade humana, diferentemente da norma ética (a exemplo da norma moral), criada pelo raciocínio humano e que impõe um dever-ser, isto é, a pessoa é vinculada a comportar-se como ela determina, sob pena de desarmonizar as relações sociais (DINIZ, 2008, p. 374-376). 
Com relação às normas éticas e as normas jurídicas, a diferença está no “autorizamento", ou seja, a norma jurídica autoriza ou não a pessoa a conduzir-se de uma forma ou outra, vedando ou reprimindo certos tipos de comportamento, enquanto as normas éticas (como as morais) são livres desde que não sejam proibidas ou restringidas pela norma jurídica. Portanto, a essência específica da norma jurídica é que autoriza quem sofreu lesão exigir que o agente que provocou a lesão repare o mal ou que o inadimplente cumpra a obrigação ajustada (DINIZ, 2008, p. 383).

Conforme Reis Friede (2009, p. 253-254) explica, o Direito é uma legítima ciência social, já que tem como requisito fundamental o "fato" social e a constante busca pela verdade, por meio de interpretação e superação daquela verdade, continuando seu ciclo científico.

Assim, o Direito é uma ciência essencialmente hermenêutica formada por um complexo processo de interpretação, composto por duas fases principais: legislativa (interpretação valorativa inicial) e judiciária (sobreinterpretação da norma), resultando na interpretação final e definitiva como "verdade relativa", comum a todas as ciências, pois, como se sabe, em ciência não se fala em verdades absolutas.

O jurista Paulo Nader (2015, p. 280) confirma esse pensamento, dizendo que o fim da lei não é aquele pensado pelo legislador, mas sim o fim que está implícito na mensagem da lei

\begin{abstract}
Como esta deve acompanhar as necessidades sociais, cumpre ao intérprete revelar os novos fins que a lei tem por missão garantir. Esta evolução de finalidade não significa ação discricionária do intérprete. Este, no afã de compatibilizar o texto com as exigências atuais, apenas atualiza o que está implícito nos princípios legais.
\end{abstract}

Nas palavras de André Franco Montoro (1997, p. 580), a sociedade influencia e atua sobre o Direito, bem como este também influencia e atua sobre a sociedade; para este jurista, o Direito nasce da sociedade e, em cada momento, ele é o resultado de um complexo de fatores sociais.

Em citação a Michel Virally, André Franco Montoro (1997, p. 581) aduz que o "fenômeno jurídico é apenas uma face de um fenômeno global, infinitamente mais complexo, que é a realidade social".

Nesse sentido, é de bom senso que a sociedade tenha maior conhecimento de noções básicas de Direito, pois que este faz parte da realidade social, de modo que o Direito emana da sociedade sob múltiplas determinantes, conforme compreendido por André 
Franco Montoro (1997, p. 581) são: “1. como resultante do poder social; 2. como reflexo dos objetivos, valores e necessidades sociais; 3. como manifestação ou efeito de fatores sociais: históricos, geográficos, técnicos, econômicos, culturais, psicológicos, morais, religiosos, etc."

O referido autor, ainda, enumera os aspectos mais comuns do Direito que são influenciados pela sociedade: "o poder social; os valores sociais; os fatores geográficos, climáticos e raciais; os fatores históricos; os fatores psicológicos; os fatores morais e religiosos; os fatores científicos e técnicos; os fatores econômicos" (MONTORO, 1997, p.581)

De outro lado, André Franco Montoro (1997, p.581) classifica a influência do Direito sobre a sociedade: "Direito como instrumento de controle social; - o reconhecimento pela comunidade; - funções da norma jurídica: função ordenadora, educativa, conservadora e transformadora".

Nesse sentido, o Conselho Nacional de Educação elaborou as Diretrizes Curriculares Nacionais (BRASIL, Ministério da Educação, 2013),

\begin{abstract}
Na elaboração dessas diretrizes, o Conselho Nacional de Educação contou com a contribuição dos seus conselheiros, de representantes dos conselhos estaduais e municipais, técnicos e servidores do CNE, especialistas, pesquisadores, integrantes de sistemas de ensino, técnicos do Ministério da Educação e representantes de entidades representativas dos trabalhadores em educação que participaram dos seminários, debates e audiências públicas com o objetivo de promover o aperfeiçoamento da educação nacional, tendo em vista o atendimento às novas demandas educacionais geradas pelas transformações sociais e econômicas e pela acelerada produção de conhecimentos.
\end{abstract}

Percebemos que as Diretrizes Curriculares Nacionais preocuparam-se por estabelecer objetivos que aprimorassem a educação, atendendo novas necessidades educacionais provocadas pelos fatos sociais. Assim, o currículo nacional está aberto a comportar disciplinas socialmente relevantes, do que se compreende que noções básicas de Direito poderiam ser uma dessas disciplinas.

O jurista alemão Rudolf Von Ihering, referenciado por Paulo Nader (2015, p.263-264), asseverou que a essência do Direito é a sua realização prática, o que significa que o Direito existe para ser sentido, vivido, aplicado e regrar a vida social com efetividade. Portanto, 
Interpretar o Direito representa revelar o seu sentido e alcance. [...] Tal objetivo requer, para ser alcançado, o conhecimento prévio da ordenação jurídica por parte de seus destinatários. Para cumprir o Direito é indispensável o seu conhecimento e este é obtido pela interpretação. Interpretar o Direito é conhecê-lo; conhecer o Direito é interpretá-lo (NADER, 2015, p. 263-264).

Nesse contexto, pergunta-se: quem são os destinatários da ordenação jurídica? São as pessoas, a sociedade, os alunos, os educandos que têm o direito de saber os seus direitos assegurados pela Constituição e pela Lei de Diretrizes Básicas da Educação.

Nesse caminho, exemplifica Paulo Nader (2015, p. 263), com muita propriedade quanto ao Direito do Trabalho, que revelar o sentido da lei é entender que quando ela concede férias ao trabalhador a sua finalidade visa a proteção e benefício à sua saúde física mental; quanto ao alcance da lei significa delimitar o seu campo de ocorrência, de incidência.

No exemplo citado, estão inclusos os trabalhadores assalariados que participam da relação empregatícia conforme as normas da Consolidação das Leis Trabalhistas, bem como a Lei do Regime Jurídico dos Servidores Públicos Civis da União, também possuem um campo limitado de incidência (NADER, 2015, p. 263).

Segundo destaca o educador José Carlos Libâneo (2004, p. 44), o mundo atual passa por transformações, em escala mundial, compondo um conjunto de fatos, acontecimentos e processos que alteram o cenário e geram novas realidades sociais, sejam elas políticas, culturais, econômicas ou geográficas, dentre os quais, se evidenciam as algumas mudanças como

\footnotetext{
- Notáveis avanços tecnológicos na microeletrônica, na informática, nas telecomunicações, na automação industrial, na biotecnologia, na engenharia genética, entre outros setores, caracterizando uma revolução tecnológica sem precedentes.

- Globalização da sociedade, internacionalização do capital e dos mercados, reestruturação do sistema de produção e do desenvolvimento econômico.

- Difusão maciça da informação, produção de novas tecnologias da comunicação e da informação, afetando a produção, circulação e consumo da cultura.

- Mudanças nos processos de produção, na organização do trabalho, nas formas de organização dos trabalha, dores, nas qualificações profissionais.

- Alterações nas concepções de Estado e das suas funções, prevalecendo o modelo neoliberal de diminuição do papel do Estado e fortalecimento das leis do mercado.

- Mudanças nos paradigmas da ciência e do conhecimento, influindo na pesquisa, na produção de conhecimentos, nos processos de ensino e aprendizagem.

- Agravamento da exclusão social, aumento da distância social e econômica entre incluídos e excluídos dos novos processos de produção e das novas formas de conhecimento.
} 
Logo, com a simples leitura das mudanças apontadas por Libâneo, facilmente podemos compreender que, cada vez mais, a realidade se torna mais complexa, dinâmica e altamente mutável, o que demanda da educação maior aprofundamento nas questões de Direito. Toda a realidade social é regrada pelo Direito, devendo a educação se movimentar para adequar-se a essas necessidades do mundo contemporâneo.

Quanto à percepção do Direito na realidade social, Paulo Nader (2015, p. 1) afirma que identificar o Direito no universo das criações humanas, entendendo-o e delimitando-o como ordem social dotada de coerção e, simultaneamente, como dispositivo de garantia da liberdade humana, é o grande objetivo do conjunto de temas que se abrem à compreensão dos alunos.

Por sua vez, José Carlos Libâneo (2004, p.46) fala de alguns desafios e problemas relacionados aos valores humanos que devem ser enfrentados pela escola

\begin{abstract}
No campo da ética, o mundo contemporâneo convive com uma crise de valores, predominando um relativismo moral baseado no interesse pessoal, na vantagem, na eficácia, sem referência a valores humanos como a dignidade, a solidariedade, a justiça, a democracia, o respeito à vida. É preciso a colaboração da escola para a revitalização da formação ética, atingindo tanto as ações cotidianas quanto as formas de relações entre povos, etnias, grupos sociais, no sentido do reconhecimento das diferenças e das identidades culturais.
\end{abstract}

Continua o educador Libâneo (2004, p. 46) dizendo que é necessária a propagação de saberes determinados e especializados

\begin{abstract}
Além disso, ao lado do conhecimento científico e da preparação para o mundo tecnológico e comunicacional é necessária a difusão de saberes socialmente úteis, entre outros, o desenvolvimento e a defesa do meio ambiente, a luta contra a violência, o racismo e a segregação social, os direitos humanos.
\end{abstract}

Portanto, José Carlos Libâneo deixou bem claro que não bastam mais transmitir somente os conhecimentos científicos e tecnológicos, mas também outros saberes que dizem respeito ao meio ambiente, direitos humanos, como o combate ao racismo, à violência e à exclusão social. Nessa direção, segue José Carlos Libâneo (2004, p. 46) dizendo que 


\begin{abstract}
A escola contemporânea precisa voltar-se para as novas realidades, ligar-se ao mundo econômico, político, cultural, mas precisa ser um baluarte contra a exclusão social. A luta contra a exclusão social e por uma sociedade justa, uma sociedade que inclua todos, passa pela escola e pelo trabalho dos professores. Propõe-se, para essa escola, um currículo centrado na formação geral e continuada de sujeitos pensantes e críticos, na preparação para uma sociedade técnica/científica/informacional, na formação para a cidadania críticoparticipativa e na formação ética.
\end{abstract}

Assim, percebe-se que o Direito é um amplo campo de conhecimentos que são indispensáveis à escola atual, conforme se depreende das palavras de José Carlos Libâneo, pois enfatiza que a escola precisa preparar uma sociedade técnica, científica e informacional para auxiliar a formação cidadã dos alunos.

Como já dito, o Direito é, por excelência, a ciência social aplicada às condutas e aos comportamentos humanos, impondo regras e estabelecendo sanções pertinentes aos casos de quebra ou descumprimento das obrigações que prejudiquem as relações sociais ou, ainda, as relações com o meio ambiente.

O conceito contemporâneo de cidadania deve ser entendido para além de simples pressuposto formal, ou seja, a cidadania está ligada à dignidade da pessoa humana, de maneira que abrange um conjunto de práticas que outorgam ao sujeito a condição de componente ativo da sociedade onde vive e que lhe dê acesso, sem qualquer discriminação, aos recursos básicos para o exercício de direitos e deveres.

Torna-se evidente que, entre esses recursos básicos, encontra-se o direito à educação de qualidade, nela incluída os mais adequados recursos básicos para exercer direitos e obrigações, cabendo uma disciplina que aborde Noções Básicas de Direito.

\title{
4 EXPERIÊNCIAS PARA INCLUIR NOÇÕES DE DIREITO NO CURRÍCULO ESCOLAR
}

Destacamos que os projetos de extensão ${ }^{2}$ desenvolvidos na comunidade escolar com apoio do Departamento de Pesquisa e Extensão da UEMG-Unidade Frutal, conseguiram a integração da teoria com a prática dos estudantes do curso de Direito, que ao exporem o tema, incentivaram os alunos ouvintes (ensino médio) a conhecerem a Ciência do Direito, buscando-a de forma espontânea no seu dia-a-dia, ajudando a construir e aprimorar a Cidadania no futuro, a fim de por em prática o aprendizado de forma mais consciente e a lutar contra as desigualdades sociais. 
Nos parâmetros ditados nos projetos de extensão, observamos que a "colaboração" EDUAÇÃO-CIDADANIA-JUSTIÇA atingiu a conscientização da construção de uma sociedade livre, justa e solidária; a garantia do desenvolvimento social; as noções para a erradicação do trabalho discriminatório feminino, do trabalho infantil, do trabalho escravo; das condições ambientais de trabalho; da redução das desigualdades sociais e regionais; a promoção do bem de todos, sem preconceitos de origem, raça, sexo, cor, idade e quaisquer outras formas de discriminação, ou seja, a "colaboração" na construção de uma cidadania efetiva, baseada na proteção e no gozo dos direitos fundamentais.

Ao ser apresentado aos alunos do ensino médio da Escola Estadual Maestro Josino de Oliveira de $1^{\circ}$ e $2^{\circ}$ Graus, noções fundamentais básicas de Direito, conseguiu-se atingir um público de 90 alunos. As palestras foram ministradas na escola referida acima, levando conhecimentos jurídicos básicos aos alunos, bem como uma efetiva participação destes alunos nas discussões dos temas, os quais trouxeram a baila situações do dia-a-dia que exigiam noções jurídicas para uma melhor compreensão em suas realidades.

Observamos que os objetivos propostos nos projetos foram alcançados. Conseguiuse apresentar aos alunos da referida escola noções fundamentais básicas de Cidadania e Justiça, relacionados aos direitos trabalhistas inseridos na Constituição Federal, Consolidação das Leis do Trabalho e legislações pertinentes ao tema, bem como Direito de Família e Sucessões. Durante as palestras, ministradas aos alunos, além dos conhecimentos levados, construiu-se uma sociedade mais consciente e harmônica, por meio da institucionalização do projeto com total apoio da Universidade e da Escola Estadual.

\footnotetext{
2 1. UEMG VAI À ESCOLA: UMA QUESTÃO DE INTEGRAÇÃO DO DIREITO E EDUCAÇÃO A CAMINHO DO CONHECIMENTO DA CIDADANIA E DOS DIREITOS CIVIS DE CADA INDIVÍDUO. Projeto de extensão desenvolvido junto ao DEPARTAMENTO DE EXTENSÃO DA UNIVERSIDADE DO ESTADO DE MINAS GERAIS sem bolsa-Edital 01/2015; 2. EDUCAÇÃO, CIDADANIA E JUSTIÇA: A “CO- LABORAÇÃO” PARA A TRANSFORMAÇÃO DAS DIMENSÕES HUMANAS E SOCIAIS. Projeto de extensão desenvolvido junto ao PROGRAMA INSTITUCIONAL DE APOIO À PESQUISA DA UEMG com bolsas no Edital Paex 01/2015; e, 3. O projeto "UEMG VAI À ESCOLA" desenvolvido na Semana UEMG de2013, como forma de se concretizar por meio da aplicabilidade, toda a teoria abordada. Diante dessas iniciativas, torna-se, ainda, mais atual e relevante o tema, pois, busca-se um maior estudo das relações sociais, econômicas e culturais que tratam de cidadania. Além disso, necessita de um maior entendimento no que tange o meio social. No desenvolver dessas pesquisas de extensão, foram utilizados como paradigmas o "Programa TCJ-Trabalho Cidadania e Justiça", desenvolvido pelo Tribunal Superior do Trabalho e "OAB vai à escola" (Seccional do Estado de São Paulo)
} 
No decorrer do desenvolvimento do projeto verificamos, ainda, uma aproximação dos acadêmicos de direito com a realidade fática-social e cidadãos, formando assim, conhecimentos corretos sobre cidadania. Nesse sentindo, os acadêmicos colocaram em prática as teorias aprendidas na universidade, com a integração dos Professores e Alunos do Curso de Direito da UEMG Frutal-MG, demais operadores do Direito com a escola, a família e a sociedade.

No Brasil, ainda mostram-se poucos e efetivos passos quanto à inclusão de uma disciplina de cunho jurídico-legal na grade curricular escolar, mas podemos ver que já existe uma Lei no Estado de Rondônia que já dá seus frutos. Em âmbito federal, é importante ressaltar que existem muitos projetos de lei, seja na Câmara dos Deputados ou no Senado Federal, que têm como objetivo introduzir conceitos e alterações na Lei de Diretrizes e Bases da Educação que visem a inclusão de disciplinas que tratem de temas ligados ao Direito (tudo ainda, em discussões).

Assim, o reconhecer da importância de cada ser humano dentro da sociedade em que vive, dimensionou-se a relevância do Estado Democrático de Direito, da Constituição e das leis na vida dos cidadãos.

\section{CONCLUSÃO}

O tema do presente trabalho não se esgota aqui, muito há de se discutir, mas, podemos dizer que a Constituição Federal de 1988 e a Lei de Diretrizes e Bases da Educação abriram as portas da autonomia para que os sistemas de ensino e as instituições escolares possam ter o poder de incluir disciplinas e conteúdos, conforme se apresentem as demandas e necessidades dos alunos, da comunidade escolar e da sociedade como um todo.

O aluno tem o direito ao acesso a uma educação de qualidade, que possa lhe formar como cidadão e o prepare para a vida em comunidade, como um sujeito que compreenda a realidade que o cerca e intervenha nela ativamente, de acordo com a compreensão adquirida na escola.

Para isso acontecer, a escola deve fornecer ao aluno a estrutura e o conteúdo necessário e adequado, de maneira que as informações e conhecimentos aprendidos no contexto escolar possam ser suficientes para lhes darem condições de entender os princípios mais valiosos preconizados pela nossa Constituição, entre eles, o princípio da 
dignidade humana, da solidariedade, do respeito às diferenças e dos seus direitos e deveres básicos previstos na legislação.

Nesse sentido, observamos que o Direito é uma ciência de cunho social e cultural, devendo ser incluída na grade curricular como um elemento fundamental para levar conhecimento específico e noções básicas de direito aos alunos, dentro de uma perspectiva de melhoria e ampliação dos conhecimentos sociais, políticos e culturais pertinentes ao Direito.

Este trabalho deixou claro que o Direito é passível de ser incluído no currículo escolar, haja vista que a própria Lei de Diretrizes e Bases da Educação já exige alguns conteúdos como os relacionados ao Direito, bem como comprovamos pelas experiências práticas aqui relatadas que comprovaram a total possibilidade de concretização de ser incluída na grade curricular a disciplina Noções Básicas de Direito.

De outro lado, a Lei de Diretrizes e Bases da Educação dá plena autonomia na parte diversificada, onde poderá a escola, por meio do seu projeto políticopedagógico, incluir matérias, disciplinas e conteúdos de interesse local e/ou regional, de modo que, entre esses, seria importante a inserção da disciplina "Noções Básicas de Direito", em todos os níveis e modalidades de ensino.

Um grande avanço no Brasil é que há liberdade concedida pela Lei de Diretrizes e Bases da Educação para que os sistemas de ensino e as escolas possam adequar e encaixar disciplinas específicas, visando uma maior abrangência de ciências sociais, sobretudo as que tratam sobre cidadania, participação popular e defesa de direitos e garantias individuais e fundamentais, asseguradas pela Constituição Federal.

Portanto, podemos afirmar que a inclusão de uma disciplina de "Noções Básicas de Direito" no currículo escolar do ensino fundamental e médio, daria frutos, principalmente, em longo prazo, preparando, informando e capacitando o aluno a ser um cidadão crítico, reflexivo, transformador e consciente dos seus direitos e deveres, contribuindo para um País melhor, uma sociedade mais justa e igualitária, cobrando melhores condutas e ações da classe política. 


\section{REFERÊNCIAS BIBLIOGRÁFICAS}

BOBBIO, Noberto. A Era dos Direitos. Trad. Carlos Nelson Coutinho. Rio de Janeiro: Campus, 1992.

BRASIL. Lei no 9.394, de 20 de dezembro de 1996. Estabelece as diretrizes e bases da educação nacional. Atualizada. Brasília: Congresso Nacional, 1996. Disponível em: http://www.planalto.gov.br/CCIVIL_03/leis/L9394.htm. Acesso em: 17/03/2016.

BRASIL. Ministério da Educação. Secretaria de Educação Básica. Secretaria de Educação Continuada, Alfabetização, Diversidade e Inclusão. Conselho Nacional da Educação. Diretrizes Curriculares Nacionais Gerais da Educação Básica. Diretoria de Currículos e Educação Integral. Brasília: MEC, SEB, DICEI, 2013. Disponível em: http://portal.mec.gov.br/index.php?option=com_docman\&view=download\&alias=13677diretrizes-educacao-basica-2013-pdf\&Itemid=30192. Acesso em: 30/03/2016.

BRASIL. Secretaria de Educação Fundamental. Parâmetros curriculares nacionais: terceiro e quarto ciclos do ensino fundamental: introdução aos parâmetros curriculares nacionais. Brasília: MEC/SEF, $1998 . \quad$ Disponível em: http://portal.mec.gov.br/seb/arquivos/pdf/introducao.pdf. Acesso em: 01/04/2016.

Constituição da República Federativa do Brasil. Disponível em: $<$ http://www.planalto.gov.br/ccivil_03/constituicao/constituicaocompilado.htm>. Acesso em 01/04/2016.

CURY, C. R. J. Direito à educação: direito à igualdade, direito à diferença. Cadernos de Pesquisa, São Paulo, n. 116, p. 245 _ 262, jul. 2002a.

Dicionário de Português Michaelis. Disponível em:

<http://michaelis.uol.com.br/moderno/portugues/index.php?lingua=portugues-portugues $>$. Acesso em: 01/04/2016.

DINIZ, Maria Helena. Compêndio de introdução à ciência do direito. 19. ed. São Paulo: Saraiva, 2008.

FRIEDE, Reis. Percepção Científica do Direito. História, São Paulo, 28 (2): 2009; 235266. Disponível em: http://www.scielo.br/pdf/his/v28n2/09.pdf. Acesso em: 01/04/2016.

LIBÂNEO, José Carlos. Organização e gestão da escola: teoria e prática. 5. ed. rev. e ampl. Goiânia-GO: Alternativa, 2004.

LIMA, Maria Cristina de Brito. A educação como direito fundamental. Rio de Janeiro: Lumen Juris, 2003.

MONTORO, André Franco. Introdução à ciência do direito. 24. ed. São Paulo: Editora Revista dos Tribunais, 1997.

NADER, Paulo. Introdução ao estudo do direito. 37. ed. rev. e atual. Rio de Janeiro: Forense, 2015. 
NEVES, L. M. W. Educação e política no Brasil de hoje. 2. ed. São Paulo: Cortez, 1999. Projeto de extensão desenvolvido junto ao DEPARTAMENTO DE EXTENSÃO DA UNIVERSIDADE DO ESTADO DE MINAS GERAIS sem bolsa-Edital 01/2015. UEMG VAI À ESCOLA: UMA QUESTÃO DE INTEGRAÇÃO DO DIREITO E EDUCAÇÃO A CAMINHO DO CONHECIMENTO DA CIDADANIA E DOS DIREITOS CIVIS DE CADA INDIVÍDUO.

Projeto de extensão desenvolvido junto ao PROGRAMA INSTITUCIONAL DE APOIO À PESQUISA DA UEMG com bolsas no Edital Paex 01/2015. EDUCAÇÃO, CIDADANIA E JUSTIÇA: A “CO-LABORAÇÃO” PARA A TRANSFORMAÇÃO DAS DIMENSÕES HUMANAS E SOCIAIS.

Projeto “UEMG VAI À ESCOLA” desenvolvido na Semana UEMG de 2013.

RANIERI, Nina. Educação Superior, Direito e Estado: Na Lei de Diretrizes e Bases (Lei 9394/96). São Paulo: Edusp, 2000.

SARLET, Ingo Wolfgang. A eficácia dos direitos fundamentais. Porto Alegre: Livraria do Advogado, 1998.a 